\title{
Pilot study on the effectiveness of telemedicine in improving the quality of diabetes care of the rural Nepal
}

\author{
Jyoti Bhattarai, Samjhana Shakya, Niraj Shrestha \\ Institute of Medicine, Department of Medicine, TU, Kathmandu, Nepal
}

\section{A B S T R A C T}

The use of telecommunication in the field of medicine is very limited in Nepal. Despite huge potential of improving access of the suburban and rural communities with the urban-based health care professionals for expert consultation, the use of the telecommunication technology remains largely unexplored. In light of the facts, a comparative study was conducted at a rural community in Makwanpur. In total 40 patients ( 20 in each group) were selected for the study with an objective to test the feasibility and effectiveness of telemedicine in improving the quality of diabetes care in an experimental group and control group in Makwanpur district. In the intervention group, diabetes care was provided with tele-consultation for diabetes care mediated via local doctor.The outcome was compared with a control group based in an urban community with treatment as usual in their community. The study results showed that the use of telemedicine is a feasible alternative to provide diabetes care in rural Nepal. Overall fasting blood sugar was better controlled in the control group whereas there was significant improvements in micro albumin were observed in the interventional group. Similarly, the knowledge of the respondents on various aspects of the disease was also found to be better in the interventional group than in the control group. Majority of the respondents $(90 \%)$ felt telemedicine service is less expensive than the service they had taken before.

Key words: Diabetes, rural, teleconsultation

\section{INTRODUCTION}

The prevention and control of diabetes is a multifaceted and complex task for the least developed countries such as Nepal. Despite an excellent hierarchy of health units at different levels, the service seekers have difficulties accessing even the basic health services primarily due to difficult topography, economic constraints and skewed distribution of major health facilities in the urban areas. Moreover, consultation services on diabetes is an expensive feat for an average Nepalese. According to a study conducted in

\begin{tabular}{|l|l|}
\hline \multicolumn{2}{|c|}{ Access this article online } \\
\hline Quick Response Code: & Website: \\
\hline & www.joshd.net \\
\hline & \\
\hline & \\
\hline
\end{tabular}

selected outpatient clinics of Kathmandu on average, the consultation fee was approximately US\$ 4 per diabetic patient while per visit cost amounted to US\$11. ${ }^{[1]}$

The technological advancements in the field of science and technology have resulted in alteration of orthodox concept of imparting health care. Today patients and medical doctors do not have to meet in person for consultation, the use of telemedicine which may be via telephone or internet has helped connect professional health workers to the needy population.

In a study designed to evaluate the impact of a tele-assistance system on the metabolic control of type 2 diabetes patients it was found that the tele-assistance system using real-time transmission of blood glucose results with an option to make telephone consultations was feasible in the primary care setting as a support tool for family physicians in their follow-up of type 2 diabetes patients. ${ }^{[2]}$ The basic functions of the telemedicine system can include tele-monitoring of

Corresponding Author: Dr. Jyoti Bhattarai, Institute of Medicine, TU, Kathmandu Nepal, Metro Clinic, Thapathali, Kathmandu, P. O. Box - 1941, Kirtipur, Nepal. E-mail: jyotikunwar@yahoo.com 
patient's blood glucose data, self-management actions, and remote care from doctors to diabetes patients. ${ }^{[3]}$ The use of telecommunications backed up by a paraprofessional outreach workers and an expert medical team of registered nurses and endocrinologists was really useful in enhancing quality of diabetes care which was manifested in the significant decrease in glycated hemoglobin to $7.2 \%$ from $9.6 \%(P=0.001)$ in a hispanic population of in United States of America. ${ }^{[4]}$

Till now there is no study in Nepal that has explored the possibility of using telemedicine to improve diabetes care. This pilot study was conducted to test the feasibility of telemedicine in improving the quality of diabetes care in rural Nepal.

\section{MATERIALS ANd Methods}

This study is a comparative-cross sectional study between two groups of diabetes patients. An interventional group (at Manari Village Development Committee, a rural community in Makwanpur) was provided with teleconsultation for diabetes care mediated via local doctor was compared with a non-interventional group/control group (chosen from $23 \mathrm{~km}$ away urban area, Hetauda). In total 40 patients were selected for the study, 20 each from the intervention and the non-intervention group were selected purposively for the study.

Patients coming to Hetauda District Hospital were followed as usual by their local physician. All participants got regular monitoring of glucose and were given diabetes self-management education (DSME) both locally by local health care workers and by team from Kathmandu intermittently.

At the beginning of the study, a diabetes camp was organized in both Manari Primary Health Care Centre and Hetauda District Hospital. Fasting and postprandial blood glucose was done on the patients coming to the clinic. A colorimeter was used to do a blood sugar. People with known diabetes (already on one or more medications) and patients who fit the diagnosis of diabetes (based on World Health Organization definition of diabetes ${ }^{[5]}$ ) during screening were identified. Patients with diabetes were given option to enroll in the study and willing patients who consented were enrolled in the study. Patient below age 30 years and above 70 years and anyone with a history of kidney or liver disease were excluded. First 20 patients who gave consent to participate in the study were chosen.
Initially baseline data was collected to obtain information on smoking and alcohol intake habit, laboratory investigation data, as well as physical activity of the respondents. Patients were followed up for a year and at the end of the study data baseline date were recollected. End line data was compared to baseline data. Likewise, data comparison was done between experimental group and control group.

The project was approved by national health research council. An informed consent was obtained from each participant. All the forms, formats and questionnaire used in the study were pre-tested, and necessary modification was done.

Moreover, an initial 1 day workshop was organized for 20 health care workers and seven doctors on diabetes care from both the groups. Ongoing mentorship and supervision was provided to local doctor/local health care worker in the intervention group via tele-technology on medical, nutritional management of diabetes. Local doctor and health worker team intermittently provided -DSME.

Descriptive statistics was used. Frequency distribution, percentage analysis, means and standard deviation was used in descriptive statistics. The analysis was carried out by Statistical Package for Social Science 16.0 (ERAA Biochemistry Analyzer).

\section{RESULTS}

The average age of the respondent in the interventional group was 45.3 years with standard deviation 8.4 years and in the control group was 50.4 years with a standard deviation 6.4 years [Table 1]. Almost, all the participants from both groups were married. Majority of the respondent from the interventional group and the control group were Aryan, and rest was Mongols [Table 2].

Most of the subjects felt, a telemedicine service is less expensive (90\%) than the service they had taken before it, and they felt it was a useful service. Most of them also reported that telemedicine was significantly cost saving in terms of travel. All of them reported it is a useful service and felt there is a necessity of such service in their community, and they highly recommended such service to other similar communities.

In the interventional group, $30 \%$ of respondents had a smoking habit which did not change even at the end of the study. Alcohol consuming habit was similar in both groups and remained constant in the intervention group in the end, but interestingly it decreased in the control group [Table 3]. 
In the interventional group, more than half of the respondents were doing regular exercises which increased by the end of the study. The study results also showed that percentage of respondents performing strenuous activities like brisk walking, working in the garden, physical exercise, etc. increased in the intervention group in comparison to the control group (55\% vs. 29\%) [Table 4].

No significant difference was observed between groups in regards to the results of the laboratory investigation except significant improvements were observed in blood sugar in

\begin{tabular}{|c|c|c|}
\hline $\begin{array}{l}\text { Demographic } \\
\text { characteristics }\end{array}$ & $\begin{array}{l}\text { Experimental group } \\
\qquad(n=20)\end{array}$ & $\begin{array}{l}\text { Control group } \\
(n=20)\end{array}$ \\
\hline \multicolumn{3}{|l|}{ Sex } \\
\hline Women & 30.0 & 15.0 \\
\hline Men & 70.0 & 85.0 \\
\hline \multicolumn{3}{|l|}{ Age group } \\
\hline $30-40$ & 20.0 & 5.0 \\
\hline $40-50$ & 55.0 & 40.0 \\
\hline $50-60$ & 15.0 & 40.0 \\
\hline 60 and above & 10.0 & 15.0 \\
\hline Mean age $\pm S D$ & $45.3 \pm 8.4$ & $50.4 \pm 6.4$ \\
\hline
\end{tabular}

\begin{tabular}{lcc}
\hline $\begin{array}{l}\text { Table 2: Caste/ethnicity and educational status } \\
\text { of the respondents in percentage }\end{array}$ \\
$\begin{array}{lcc}\text { Socioeconomic } \\
\text { characteristics }\end{array}$ & $\begin{array}{c}\text { Experimental group } \\
(\boldsymbol{n}=\mathbf{2 0})\end{array}$ & $\begin{array}{c}\text { Control group } \\
(\boldsymbol{n}=\mathbf{2 0})\end{array}$ \\
\hline $\begin{array}{l}\text { Caste/ethnicity } \\
\text { Aryan }\end{array}$ & 80.0 & 85.0 \\
$\quad$ Mongol & 20.0 & 15.0 \\
$\begin{array}{l}\text { Educational status } \\
\text { Illiterate }\end{array}$ & 25 & 20 \\
Literate & 75.0 & 80.0 \\
\hline
\end{tabular}

\begin{tabular}{lccccc}
\hline $\begin{array}{l}\text { Table 3: Smoking and alcohol consumption habits } \\
\text { of respondents }\end{array}$ & \multicolumn{3}{c}{$\begin{array}{c}\text { Experimental group } \\
(\boldsymbol{n}=\mathbf{2 0})\end{array}$} & & \multicolumn{2}{c}{$\begin{array}{c}\text { Control group } \\
(\boldsymbol{n}=\mathbf{1 7})\end{array}$} \\
\cline { 2 - 3 } \cline { 5 - 6 } Activity & Baseline & End line & & Baseline & End line \\
\hline Smoking habit & 30.0 & 30.0 & & 35.3 & 35.3 \\
Soft drinking habit & 20.0 & 40.0 & & 41.2 & 29.4 \\
Hard drinking habit & 15.0 & 15.0 & & 41.2 & 23.5 \\
\hline
\end{tabular}

\begin{tabular}{|c|c|c|c|c|}
\hline \multirow{2}{*}{$\begin{array}{l}\text { Physical activity of the } \\
\text { respondents } \\
\text { Regular exercise }\end{array}$} & \multicolumn{2}{|c|}{$\begin{array}{l}\text { Experimental } \\
\text { group }(n=20)\end{array}$} & \multicolumn{2}{|c|}{$\begin{array}{l}\text { Control group } \\
\quad(n=17)\end{array}$} \\
\hline & 55.0 & 70.0 & 47.1 & 70.6 \\
\hline $\begin{array}{l}\text { Utilization of leisure work by } \\
\text { the respondent }\end{array}$ & \multicolumn{2}{|c|}{$\begin{array}{l}\text { Experimental } \\
\text { group }(n=20)\end{array}$} & \multicolumn{2}{|c|}{$\begin{array}{l}\text { Experimental } \\
\text { group }(n=17)\end{array}$} \\
\hline Activity & Baseline & End line & Baseline & End line \\
\hline Mild intensity activities & 10.0 & 0.0 & 0 & 0 \\
\hline Moderate intensity activities & 65.0 & 20.0 & 47.1 & 17.6 \\
\hline Strenuous activities & 25.0 & 80.0 & 52.9 & 82.4 \\
\hline
\end{tabular}

the control group and improvement of micro albumin in the intervention group [Table 5].

Similarly, the knowledge of the respondents on various aspects of the disease was also found to be better in the interventional group than in the control group [Tables 6-8].

It the first telemedicine service experience for the interventional group. In the interventional group, before

\begin{tabular}{|c|c|c|c|c|}
\hline \multirow{2}{*}{$\begin{array}{l}\text { Mean } \pm \text { SD of } \\
\text { the following }\end{array}$} & \multicolumn{2}{|c|}{ Experimental group } & \multicolumn{2}{|c|}{ Control group } \\
\hline & Baseline & End line & Baseline & End line \\
\hline $\begin{array}{l}\text { Blood sugar } \\
\text { fasting } * *\end{array}$ & $189 \pm 94.2$ & $171.0 \pm 77.0$ & $241.7 \pm 117.4$ & $170.7 \pm 62.0$ \\
\hline$P P^{a *, b *}$ & $295.6 \pm 103.0$ & $166.3 \pm 87.1$ & $341 \pm 140.2$ & $202.5 \pm 77.9$ \\
\hline Creatnine ${ }^{a *, b *}$ & $98.0 \pm 15.1$ & $83.2 \pm$ & 5.6 & \pm 17.9 \\
\hline $\mathrm{SGPT}^{\mathrm{b} * \star}$ & $38.3 \pm 16.5$ & $37.6 \pm 24.9$ & $42.7 \pm 21.3$ & $31.6 \pm 10.3$ \\
\hline $\mathrm{TC}^{\mathrm{a} *, \mathrm{~b} *}$ & $5.4 \pm 1.0$ & $4.9 \pm 1.0$ & $5.6 \pm 1.4$ & $4.7 \pm 1.1$ \\
\hline $\mathrm{TG}^{\mathrm{c} * *, \mathrm{~d} * \star *}$ & $2.3 \pm 1.0$ & $1.9 \pm$ & $3.4 \pm 2.0$ & $3.1 \pm 2.4$ \\
\hline $\mathrm{HDL}^{\mathrm{a} \star \star \star, c \star \star \star \star, d * \star \star}$ & $1.2 \pm 0.3$ & $1.1 \pm 0.2$ & $1.1 \pm 0.2$ & $1.0 \pm 0.2$ \\
\hline $\operatorname{LDL}^{\mathrm{d} * *}$ & $2.8 \pm 0.6$ & $2.8 \pm$ & $2.4 \pm 0.9$ & $2.0 \pm 1.2$ \\
\hline $\mathrm{HBA} 1 \mathrm{C}^{\mathrm{b} * \star \star}$ & $8.0 \pm 2.0$ & $8.9 \pm 2.5$ & $7.8 \pm 2.5$ & $8.7 \pm 1.9$ \\
\hline Micro albumin ${ }^{a * \star *}$ & $85.9 \pm 109.4$ & $40.3 \pm 60.7$ & $54.5 \pm 59.0$ & $53.4 \pm 67.8$ \\
\hline $\begin{array}{l}\text { Systolic blood } \\
\text { pressure }^{d * \star}\end{array}$ & $121.5 \pm 23.2$ & $122.9 \pm 18.2$ & $132.9 \pm 21.1$ & $138.3 \pm 22.4$ \\
\hline $\begin{array}{l}\text { Diastolic blood } \\
\text { pressure }^{\mathrm{c} * \star \star, d * \star}\end{array}$ & $76.5 \pm 11.8$ & $74.1 \pm 9.9$ & $83.8 \pm 11.7$ & $82.1 \pm 12.1$ \\
\hline Weight & $63.4 \pm 11.2$ & $62.5 \pm 10.6$ & $66.6 \pm 11.2$ & $66.5 \pm 11.2$ \\
\hline \multicolumn{5}{|c|}{ 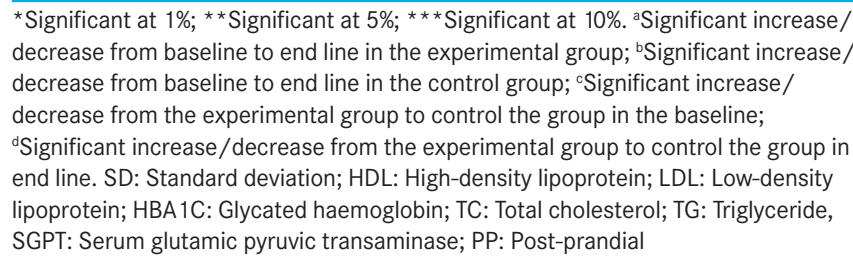 } \\
\hline
\end{tabular}

\begin{tabular}{lcc}
\hline \multicolumn{3}{l}{ Table 6: Knowledge on diabetes in percentage } \\
\hline Meaning of diabetes & Experimental group & Control group \\
\hline Increased sugar in the blood & 85.0 & 47.1 \\
Increased sugar in the urine & 10.0 & 0.0 \\
Liver failure & 5.0 & 0.0 \\
Others & 5.0 & 52.9 \\
Part of the body affected & & \\
Eye & 100.0 & 88.2 \\
Heart & 100.0 & 64.7 \\
Stroke & 20.0 & 5.9 \\
Kidney & 100.0 & 70.6 \\
Leg & 100.0 & 17.6 \\
$\quad$ Teeth & 10.0 & 0.0 \\
Should have to check eye & 95.0 & 94.1 \\
\hline
\end{tabular}

\begin{tabular}{|c|c|c|}
\hline Methods of management & Frequency & Percentage \\
\hline Taking medicine & 8 & 40 \\
\hline Regular exercise & 4 & 20 \\
\hline Controlling food habit & 7 & 35 \\
\hline Nothing were done & 2 & 10 \\
\hline Total & 20 & 100 \\
\hline
\end{tabular}




\begin{tabular}{lcc}
\hline \multicolumn{3}{l}{ Table 8: Cost benefit of telemedicine in percentage } \\
\hline $\begin{array}{l}\text { Cost benefits } \\
\text { understanding patients }\end{array}$ & Frequency & Percentage \\
\hline As same as others & 2 & 10 \\
Less expensive than other & 18 & 90 \\
$\quad$ Total & 20 & 100 \\
Travelling expenses & 1 & 5 \\
As same as others & 19 & 95 \\
Less expensive than other & 20 & 100 \\
Total & & \\
\hline
\end{tabular}

implementation of this service, they were attempting to manage their disease by following means $40 \%$ were taking medications, followed by diet control-35\%, regular exercise-20\%) and $10 \%$ of them did none of it.

\section{DISCUSSION}

This study demonstrates that the use of telemedicine in management of diabetes in rural Nepal is feasible and comparable to treatment as usual in the urban area. The results do not show much difference between the biochemical parameters between the interventional and the control group except for the significant improvements observed in blood sugar in the control group and improvement of micro albumin in the intervention group. This could be due to small size or short period of the study. This study shows that the use of telemedicine in the diabetic population will lead to increase physical activity as well as increased understanding of disease and complications, which could ultimately translate to better outcome for these patients. Most of the subjects in this study felt that telemedicine service is less expensive and that it was a useful service. Most of them also reported that telemedicine was significantly cost saving in terms of travel. Most of the subjects felt that it is a useful and needed service which they would readily recommend to other similar communities. This clearly exhibits that the use of telemedicine is acceptable and useful tool for delivery of diabetic care in this population.
The finding of this study should be taken with caution as this study is very small (only 40 subjects).

\section{CONCLUSION}

This pilot study demonstrates that the use of telemedicine in rural Nepal is feasible and can be useful tool to access specialized services in a rural community, especially where such services are not available. In future, larger, controlled studies are needed to exploit the full usefulness of telemedicine, which could been an important tool in delivery of specialized health care in country like ours where there are lot of rural communities with limited health care access.

\section{REFERENCES}

1. Shrestha N, Lohani SP, Angdembe MR, Bhattarai K, Bhattarai J. Cost of diabetes mellitus care among patients attending selected outpatient clinics. JNMA J Nepal Med Assoc 2013;52:343-8.

2. Rodríguez-Idígoras MI, Sepúlveda-Muñoz J, Sánchez-GarridoEscudero R, Martínez-González JL, Escolar-Castelló JL, Paniagua-Gómez IM, et al. Telemedicine influence on the follow-up of type 2 diabetes patients. Diabetes Technol Ther 2009;11:431-7.

3. Gómez EJ, del Pozo F, Hernando ME. Telemedicine for diabetes care: The Diabtel approach towards diabetes telecare. Med Inform (Lond) 1996;21:283-95.

4. Mayes PA, Silvers A, Prendergast JJ. New direction for enhancing quality in diabetes care: Utilizing telecommunications and paraprofessional outreach workers backed by an expert medical team. Telemed J E Health 2010;16:358-63.

5. World Health Organization. The World Health Report Primary Health Care: Now More than Ever 2008. Available from: http:// www.who.int/whr/2008/whr08_en.pdf.

How to cite this article: Bhattarai J, Shakya S, Shrestha N. Pilot study on the effectiveness of telemedicine in improving the quality of diabetes care of the rural Nepal. J Soc Health Diabetes 2015;3:52-5.

Source of Support: Nil. Conflict of Interest: None declared. 